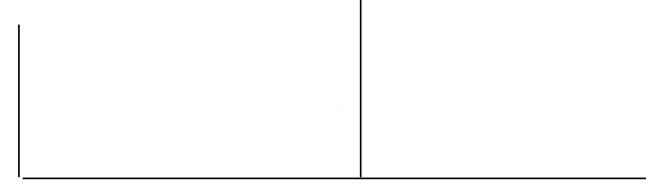

Rev. Latinoam. Psicopat. Fund., VIII, 1, 14-29

\title{
Corpo, formas, movimentos e ritmo como precursores da emergência da intersubjetividade e da palavra no bebê (Uma reflexão sobre os inícios da linguagem verbal)*
}

\author{
Bernard Golse \\ Valérie Desjardins
}

\begin{abstract}
Depois de lembrar as bases da comunicação analógica e digital, os autores apresentam as hipóteses de seu programa de pesquisa atual a respeito dos precursores corporais e comportamentais do acesso à linguagem verbal na criança. As análises do olhar, das vocalizações e dos movimentos das mãos do bebê são os principais elementos estudados nesta pesquisa colaborativa. O surgimento da intersubjetividade parece depender fundamentalmente de um equilibrio entre os processos de desmantelamento intersensorial e de segmentação intrasensorial dos diferentes fluxos perceptivos.
\end{abstract}

Palavras-chave: Bebê, comunicação, linguagem, fluxos sensoriais

* Este artigo foi publicado no Journal de Psychanalyse de l'Enfant, 35, p. 171-91, 2004. Tradução de Regina Orth de Aragão. 
Não era que o nome estivesse longe, ele estava ali, bem perto dele, na ponta de sua língua. Ele flutuava em torno de sua boca como uma sombra. (O nome na ponta da língua, de Pascal Guignard, 1993)

\section{Introdução}

O conjunto deste trabalho é o fruto de uma colaboração que se origina do nosso encontro em torno dos dois campos: o da linguagem e o da música.

A proposta de interação desses dois domínios deu nascimento a um programa de pesquisas intitulado PILE (Programme International pour le Langage de l'Enfant). ${ }^{1}$

Nele são especialmente levados em conta os precursores corporais e comportamentais do acesso à linguagem verbal, entre os quais poderiam talvez ser percebidos sinais de detecção precoce ou fatores de risco de disfasias (formas extremas e complexas de atrasos de linguagem da criança, que não podem, até agora, ser afirmadas com certeza antes da idade dos cinco ou seis anos), ou mesmo os sinais de alerta dos distúrbios graves de comunicação (no campo do autismo infantil ou das psicoses precoces, por exemplo).

Três domínios-alvo foram assim escolhidos: a análise estrutural dos vocalizes do bebê, o estudo dos movimentos dos pés e das mãos do bebê, e, por fim, o estudo do olhar do bebê e de seus movimentos oculares, tudo isso de maneira concomitante e sinérgica, sobre o fundo da análise das interações pais-bebê e das verbalizações pelo adulto.

1. Programa Internacional pela Linguagem da Criança. 
Por sua proposição de uma colaboração original quanto à análise e quanto ao tratamento das imagens entre, de um lado, psiquiatras infantis, psicólogos e psicanalistas, e, de outro, matemáticos e estatísticos, esse programa de pesquisas pretende ser exemplar de uma nova abordagem transdisciplinar do desenvolvimento do bebê e de seus distúrbios.

Depois de lembrar brevemente os dados essenciais relativos aos dois grandes tipos de comunicação (analógica e digital), apresentaremos nossas hipóteses iniciais, antes de mostrar como o bebê nos ajuda a passar de um estruturalismo dos estados a um neo-estruturalismo das formas fixas e dos movimentos, e concluiremos com a apresentação de alguns resultados preliminares a respeito dos vocalizes.

\section{Os dois grandes tipos de comunicação (e sua intrincação no seio mesmo da linguagem verbal)}

Tomou-se clássico opor os dois grandes registros da comunicação que são a comunicação "analógica" (infraverbal ou pré-verbal ou pré-lingüística), de um lado, e a comunicação "digital" (verbal ou lingüística), de outro.

De certo ponto de vista, tudo as separa, tudo as opõe.

A comunicação analógica seria principalmente suportada pelo hemisfério cerebral menor (o direito dos destros); ela seria especialmente de tipo sintético e veicularia principalmente emoções ou afetos, e isso pelo viés de elementos não codificados, no sentido dos signos saussurianos, mas muito mais globais e analógicos, em referência ao material a ser transmitido (daí a escolha desse termo para defini-la).

Quanto à comunicação digital, seria suportada pelo hemisfério maior (o esquerdo para os destros); ela seria especialmente de tipo analítico e veicularia principalmente conceitos, e isso pelo viés de elementos codificados de tipo "dígitos" de informação (daí a escolha de seu termo genérico).

Dito de outro modo, a comunicação analógica concerniria principalmente à transmissão não-verbal de mensagens de tipo emocional ou afetivo, por meio de comportamentos não lingüísticos (mímicas, olhares, gestual...), enquanto a comunicação digital referir-se-ia principalmente à transmissão verbal de mensagens de tipo conceitual ou ideativo, por meio de comportamentos lingüísticos (palavras, frases, locuções...)

No entanto, seria redutor querer fazer da comunicação analógica um equivalente da comunicação pré-verbal, e da comunicação digital um sinônimo da comunicação verbal. 
Da mesma forma, seria ilusório pensar que a comunicação analógica estaria somente do lado da metonímia, e a comunicação digital somente do lado da metáfora.

Com efeito, as coisas são evidentemente mais intrincadas.

Gostaríamos de insistir no fato de que há, na realidade, uma concatenação cerrada entre esses dois tipos de comunicação, e que cada uma delas pode servir conjuntamente aos propósitos metonímicos e metafóricos (o que remete ao conceito de "oscilação metaforo-metonímica" de G. Rosolato) e principalmente que há do analógico no digital - se podemos ousar nos expressar assim -, isto é, que existe uma parte não-verbal do próprio verbal, que é a música da linguagem.

Essa última noção é essencial para compreender a entrada do in-fans na ordem da linguagem.

A cadeia falada compõe-se efetivamente de um conteúdo e de um continente.

A idéia de conteúdo verbal remete aos elementos do enunciado (fonemas, monemas, sílabas, palavras ou frases segundo o tipo de recorte que adotamos e que se materializa nos conceitos de léxico ou de semântica).

A idéia de continente verbal remete, de um lado, às regras da enunciação que organizam o enunciado (gramática ou sintaxe) e, de outro, à música da linguagem (prosódia, timbre, tom e intensidade da voz, ritmo, débito, silêncios...).

Mas o continente é também, de uma certa maneira, o conteúdo da palavra, no sentido de que ele é o coração desta, pois é primeiro na gênese em relação ao conteúdo. Na constituição da palavra, parece também que é o conteúdo que busca adaptar-se ao continente, o continente é o que dá o sentido profundo de uma palavra, mas, por outro lado, quando escutamos alguém, o conteúdo funciona também como um continente, porque ele guia e sustenta a escuta.

A cadeia falada se compõe, assim, de uma parte segmentária, ou melhor, passível de ser segmentada, a saber, seu enunciado lingüístico propriamente dito, e de uma parte não segmentária, não passível de segmentação ou supra-segmentar, a saber, sua enunciação de tipo musical (daí a importância do que se denomina o "tom" no jogo teatral).

A parte segmentária da linguagem verbal veicula a parte cognitiva propriamente dita da mensagem, ou seja, a parte verdadeiramente ideativa do enunciado, enquanto sua parte supra-segmentar veicula provavelmente a parte mais emocional e motivacional dela, isto é, a expressão das condições afetivas de sua enunciação.

O que importa sublinhar no contexto destas páginas, é que o bebê, contrariamente ao que F. Dolto e outros sustentaram em seu tempo, não entraria na linguagem pela parte simbólica e digital desta, mas sim por sua parte afetiva e analógica. 
O bebê, com efeito, parece muito mais sensível, de início, à música da linguagem e dos sons (os que ele ouve e os que ele produz) do que à significação dos signos enquanto tais (a integração da ligação entre significante e significado sendo, sem dúvida, mais ligada a uma aprendizagem do que a uma espécie de revelação imediata).

Para entrar na ordem da linguagem (e do simbólico verbal) o bebê precisa - não saber -, mas experimentar e sentir profundamente que a linguagem do outro (e singularmente a de sua mãe) o toca e o afeta, e que esta é afetada e tocada, por sua vez, pelas primeiras emissões vocais dele.

É por isso que, no campo do desenvolvimento precoce, a lingüística saussuriana nos dá, sem dúvida, uma menor contribuição do que uma lingüística mais dinâmica e subjetal (J.L. Austin, J.S. Bruner), porque parece que nesse campo precisamos mais de uma lingüística da enunciação do que de uma lingüística do enunciado, a exemplo dos trabalhos do E. Eco, que centra seu olhar mais sobre as condições dinâmicas da produção dos signos do que sobre a organização estática dos mesmos.

Nessa perspectiva, compreende-se bem o impacto possível das depressões maternas sobre a instauração e o desenvolvimento da linguagem na criança, na medida em que essas depressões afetam, por vezes profundamente, as qualidades da voz e da música da linguagem da mãe.

Se a voz da mãe não faz nada a ele, e se as emissões vocais do bebê não fazem nada à mãe, absorvida demais em seu movimento depressivo ou em qualquer outro movimento psicopatológico, então, do ponto de vista do bebê: "para que serve falar?".

São estas as principais evocações que queríamos fazer, antes de apresentar agora nossas hipóteses iniciais.

\section{Nossas hipóteses iniciais}

O bebê constrói-se a partir dos movimentos que vêm do exterior (o exterior remetendo, aqui, ao que é percebido como tal pelo observador terceiro), esses movimentos compreendendo tanto os movimentos do corpo e da voz da mãe como também os do bebê.

A idéia de se interessar primeiro pelos movimentos corporais do bebê vem, de fato, da idéia de que as capacidades de narração verbal originam-se na realidade na aptidão do bebê a uma narração comportamental ou préverbal pela qual a criança "conta" alguma coisa de seu vivido e de sua história (B. Golse). 
Essa narração analógica ou pré-verbal precede a emergência da narração verbal que ela prepara e eventualmente condiciona, ainda que não se trate de um encadeamento linear entre esses dois tipos de narratividade, já que a narratividade pré-verbal (comunicação de tipo analógico) persistirá, durante toda a vida, ao lado da narratividade verbal (comunicação de tipo digital) da qual ela representa uma espécie de sombra permanente.

Em outras palavras, as raízes de alguns atrasos de linguagem, e especialmente das disfasias, devem ser buscadas fora da linguagem verbal propriamente dita, no campo da comunicação analógica, e no registro das interações e das emoções ao qual essa remete fundamentalmente.

\section{Os movimentos das mãos}

Alguns trabalhos já mostraram que o bebê tem movimentos específicos de seus membros superiores quando se dirige a palavra a ele, movimentos lentos e movimentos mais rápidos, com um equilíbrio dinâmico provavelmente sutil entre os dois.

Decidimos então nos centrar, na perspectiva de uma abordagem global, no estudo dos vocalizes e dos movimentos dos membros do bebê em situação dialógica, ou seja, num enquadre relativamente próximo daquele proposto por E. Fivaz-Depeursinge e colaboradores, em Lausanne, com o nome de "Trilogie Play Lausanne" (TPL).

Quando falamos, fazemos quase sempre movimentos com os braços e com as mãos. É possível que existam a esse respeito variações socioculturais ("falase mais com as mãos" em alguns países do que em outros), mas é difícil imaginar um locutor estritamente imóvel, salvo se for para colocar seu interlocutor numa situação de perplexidade e de estranheza mais ou menos inquietantes.

Qual é então a função desses movimentos de acompanhamento da linguagem verbal, movimentos que parecem tão importantes, mas que, no entanto, não mudam nada ao teor conceitual da mensagem verbal propriamente dita?

Trata-se de uma questão delicada, mas apaixonante.

Três pistas de reflexão nos parecem possíveis, por ora.

- Em primeiro lugar, podemos imaginar que esses movimentos revestem um valor defensivo pelo viés de um "envelope de agitação motora" (D. Anzieu) em relação à vulnerabilidade narcísica própria a qualquer tomada de palavra. Falar comporta efetivamente sempre um risco: o risco de não ser compreendido, de ser mal compreendido ou de ser mal julgado, até que não se tenha chegado ao final de sua frase ou de sua exposição.

Entre o início da frase e o final dela, abre-se inelutavelmente uma espécie de hiância narcísica que leva, aliás, alguns sujeitos a falar muito depressa, em uma 
tentativa freqüentemente ilusória de tampar um pouco que seja este período de vulnerabilidade (um pouco à moda das crianças que descobrem a marcha, mas que, estando ainda instáveis, correm ao invés de caminhar, para tentar reduzir o lapso de tempo entre o apoio deixado e o apoio reencontrado). Esta vulnerabilidade narcísica da criança quando das primeiras tomadas de palavra será, em seguida, ulteriormente reforçada (ou substituída?) por uma fragilização ligada ao afluxo dos fantasmas sexuais e isso, principalmente, quando da expressão lingüística no momento da puberdade.

Tal é a antinomia entre a linguagem e o pensamento: este se desenvolve sincronicamente (no instante), enquanto aquela se desenvolve diacronicamente (no tempo), o que equivale dizer que a frase tem uma duração incompreensível enquanto o pensamento encontra-se livre desse lastro temporal.

Movimentar-se quando se fala teria, assim, uma função em relação ao desenvolvimento, mas também uma função de defesa em relação às angústias intrinsecamente ligadas ao ato da fala.

- Mas isso não basta para a compreensão desses movimentos de acompanhamento, porque não se trata de quaisquer movimentos. Os movimentos característicos são aqueles dos braços e das mãos, em uma espécie de movimento circular antero-posterior, as mãos se propulsando para o alto e para frente, para voltar em seguida para si seguindo a direção de baixo e para trás.

Esses movimentos evocaram para nós as famosas "correntes de retorno" descritas por G. Haag nos bebês de alguns meses que, ao aceder à intersubjetividade, descobrem de alguma maneira o circuito da comunicação e o figuram, assim, nesses movimentos das mãos tendo então valor de uma imagem motora.

Tudo se passa, diz G. Haag, como se esses bebês quisessem nos "demonstrar" que eles sentiram que é possível enviar a um outro, diferente de si, alguma coisa de si mesmo (uma mensagem, ou também uma "e-moção") e que esse material psíquico ou protopsíquico vai em seguida encontrar no outro um fundo a partir do qual ele poderá voltar para o emissário.

Esses movimentos das mãos teriam assim valor de relato, no sentido de que, em paralelo à linguagem verbal instaurada, eles continuariam, de uma certa maneira, a nos contar analogicamente alguma coisa sobre o próprio nascimento da comunicação.

Dois relatos se ladeariam assim, historicamente defasados: um relato analógico das origens e da descoberta da comunicação, em duplo do relato digital, isto é, do relato verbal atual. Dois tempos do relato e dois modos do relato, que nos remetem talvez à questão da "identidade narrativa" do ser humano, tão cara a P. Ricoeur. 
- Enfim, last but not least, as mãos do bebê têm um papel central pelo fato de que, inicialmente incluídas visualmente para o bebê no conjunto dos movimentos que o envolvem, elas podem ser progressivamente dominadas por ele, e sentidas como controláveis. Esses movimentos de acompanhamento da linguagem verbal ocupam, assim, um lugar central no processo de acesso à intersubjetividade, e na emergência de um verdadeiro processo de apropriação, pela criança, de seu sistema de comunicação.

\section{O olhar}

O olhar do bebê não serve talvez essencialmente para perceber as configurações estáticas, mas também e, principalmente, para perceber movimentos em referência a formas fixas, pois não há percepção possível de um mundo imóvel.

O movimento pode ser um dado do objeto, mas ele pode igualmente ser conferido ao objeto atribuído pelo fenômeno de segmentação, a respeito do qual falaremos mais adiante (piscar das pálpebras e movimentos das pupilas, por exemplo).

Os vocalizes

Como reveremos mais adiante, não há co-modalidade possível sem uma real articulação dos ritmos próprios a cada modalidade sensorial, o que exclui a possibilidade de um autêntico caos sonoro. ${ }^{2}$

Por isso, já que o bebê funciona essencialmente em co-modalidade, isso supõe um tratamento possível do "objeto sonoro" (S. Maiello) que não seja interpretado, mesmo a posteriori, em termos de perda ou de ausência, mas de início em termos de estrutura dinâmica e complexa incluindo variações de ritmo mais ou menos irregulares.

Os vocalizes do bebê não podem ser inicialmente dissociados por ele dos outros estímulos sonoros de seu ambiente (a voz da mãe, principalmente), e são as especificidades desse ambiente interativo que vão permitir que se dê uma colocação em fase rítmica das percepções sensitivo-sensoriais do bebê.

Levando em conta esses processos co-modais, para o bebê, seus vocalizes e suas primeiras palavras não são somente ar dentro de uma boca vazia. Pelo viés

2. A música contemporânea fez descobrir a possibilidade de escrituras musicais dando a ilusão de caos, sendo que, na verdade, elas são marcadamente organizadas, e que a escuta de um som totalmente caótico é, na realidade, absolutamente impossível. 
da co-modalidade perceptiva, elas são, de início, percebidas por ele como uma verdadeira "substância" sonora que preenche a cavidade bucal, e sabemos que N. Abraham e M. Torok mostraram que para aceder à linguagem e à possível simbolização dos objetos ausentes, é preciso que a boca esteja inicialmente "vazia de seio" antes de "poder se encher de palavras".

É isso também o que nos ensinam as crianças autistas, para as quais falar e emitir sons pode dar lugar a profundas angústias arcaicas de tipo não somente de perda, mas do arrancar de uma parte de si (F. Tustin), o que podemos encontrar no material dos tratamentos, e, notadamente, em alguns mutismos psicóticos que podem remeter ao medo de que as palavras emitidas venham a cair no abismo de um espaço intersubjetivo tão doloroso a admitir para esses pacientes.

Falar, para os sujeitos com patologias graves, pode vir a ser sentido em termos de perda das palavras pronunciadas, ou seja, de palavras-substância invisíveis, e, por isso, os movimentos das mãos descritos acima poderiam eventualmente dar testemunho da necessidade, para o bebê, de recuperar pela visão, pela cenestesia e pelo toque (visão e sensação do movimento de suas próprias mãos) a eventual vivência de perda que se vincula originalmente à linguagem.

Com efeito, para o bebê que funciona em co-modalidade e em transmodalidade perceptivas, a visão do afastamento e da aproximação das mãos (durante seus movimentos em corrente) viria ao mesmo tempo testemunhar a vivência de perda das palavras emitidas (tradução co-modal) e obturar essa perda por uma recuperação visual (defesa trans-modal).

\section{Por um neo-estruturalismo das formas fixas e dos movimentos}

No debate atual sobre os modos de acesso à intersubjetividade (condição de acesso à linguagem verbal), sabemos a polêmica que existe, hoje, entre os defensores de um período de indiferenciação primária (tal como evocada pelos principais modelos psicanalíticos clássicos), e os defensores de uma intersubjetividade primária fundada sobre as competências precoces do bebê nos diferentes campos da percepção, da representação, da memorização e dos processos de "agencialização"33 (D.N. Stern, C. Trevarthen).

3. "Processus d'agentialisation" ou de "agentivité" é um termo derivado das ciências cognitivas que significa que o sujeito (no caso o bebê) pode se sentir como o agente de suas próprias ações. (Nota da tradutora, segundo esclarecimento de B. Golse). 
Podemos pensar que existe uma terceira via dialética, e mais dinâmica, entre essas duas abordagens.

A idéia é a de que existiriam, de início, momentos de intersubjetividade primária que demandariam ser progressivamente trabalhados e unificados a fim de levar o bebê, pouco a pouco, a uma intersubjetividade estabilizada. O papel do funcionamento do objeto materno é, evidentemente, essencial para permitir esta confluência gradual desses momentos de intersubjetividade primária.

De todo modo, sentimos doravante que a questão não é mais tanto aquela de um estruturalismo dos estados (estado intersubjetivo versus estado não intersubjetivo), mas, sim, aquela de um neo-estruturalismo da dinâmica que permite a transição de um estado para o outro.

Esta passagem de um estruturalismo dos estados para um neo-estruturalismo dos processos (estruturalismo dos movimentos em referência às formas fixas) é particularmente sensível no campo do estudo do bebê e de seus processos de comunicação que, somente ele, poderia permitir uma tal mudança de vértice.

É por isso que iremos agora colocar alguns marcos indicadores a propósito dos diversos conceitos-chave para a compreensão da ontogênese psíquica.

\section{Co-modalidade perceptiva e movimentos}

O conceito de percepção em co-modalidade remete, na verdade, a duas experiências diferentes: ou o objeto é percebido por nossos cinco sentidos simultaneamente (como é o habitual, no adulto), ou o objeto é percebido por um só sentido de cada vez (segundo o mecanismo de desmantelamento, normal ou patológico, sobre o qual voltaremos), mas esta modalidade sensorial vem recrutar as outras modalidades sensoriais no seio mesmo do aparelho psíquico do sujeito. No primeiro caso, e é o que faz de toda percepção um fenômeno eminentemente complexo, cada modalidade sensorial recruta igualmente as quatro outras, o que um autor como W.R. Bion evocava, talvez, com seu conceito de "senso comum".

É importante assinalar aqui, como já o fizeram Ph. Mazet e H. Sitbon, que existe uma dialética entre a aptidão do bebê à co-modalidade perceptiva e as capacidades maternas de harmonização afetiva transmodal, dialética constituindo, talvez, uma das raízes da metaforização na espécie humana.

A partir daqui, a questão é saber como o bebê integra o movimento, sendo que ele justamente só dispõe de cinco modos perceptivos? Já que a percepção é de tipo co-modal, já que o movimento forma o cerne da percepção e já que o movimento só pode ser tratado por segmentação, necessário é admitir que o movimento só pode ser percebido por co-modalidade ritmada.

$\mathrm{O}$ tratamento das informações sensoriais por segmentação pode definir-se pelos quatro parâmetros seguintes: a impulsão rítmica, o tempo, a pulsação e a 
dinâmica, noções a propósito das quais remetemos o leitor às definições musicais desses termos.

Cada modalidade sensorial é ritmada com as pulsações variáveis, mas a comodalidade só pode se organizar se, e somente se, cada modalidade sensorial reconhece uma organização rítmica compatível com as das demais modalidades sensoriais, compatibilidade que, sem dúvida, não é dada de início, mas que é fruto de uma harmonização progressiva das interações. ${ }^{4}$

Vemos como se organiza a possibilidade de pontos de captura autística em caso de disfuncionamento interativo não permitindo a arrumação em ritmo das diferentes modalidades sensoriais, levando assim a uma prevalência da continuidade, base de uma temporalidade lisa, mortífera e dessubjetivante.

\section{Desmantelamento, segmentação e inter-subjetividade}

D. Meltzer propôs o conceito de "desmantelamento" que, segundo sua perspectiva, é um mecanismo de defesa permitindo à criança autista não ficar submergida pelas sensações emanadas do ambiente, graças à clivagem intersensorial de suas diferentes percepções.

Assim, a criança autista trataria os objetos sensação por sensação, e certas estereotipias (de tamborilar, de cheirar ou de lamber) podem ser compreendidas como uma maneira de entrar em contato com o objeto, mas pelo viés de uma única modalidade sensorial assim privilegiada.

Após esses trabalhos, pensou-se que esse mecanismo estava também em ação nos bebês comuns bem no início da vida, mas que esses, diferentemente talvez das futuras crianças autistas, chegavam a efetuar um trabalho de "mantelamento" de suas sensações durante alguns momentos interativos privilegiados, especialmente durante a mamada, que D. Meltzer conceitua como "um momento de atração consensual máximo".

Mas, por outro lado, vimos acima que a segmentação dos diferentes fluxos sensitivo-sensoriais era indispensável para permitir a percepção e que se trata, aqui, de um mecanismo intra-sensorial, diferentemente do desmantelamento que é um mecanismo intersensorial.

No momento da mamada, segundo D. Meltzer, o bebê, ao juntar as diversas sensações vindas do objeto materno teria, fugidiamente, a experiência de sentir ou de vivenciar a existência de um ponto exterior a ele do qual viriam simultaneamente suas diversas sensações e sua satisfação.

4. É essa noção de compatibilidade rítmica que nos permite, durante a escuta musical, ouvir vários instrumentos simultaneamente, ao mesmo tempo em que os distinguimos uns dos outros. 
$\mathrm{O}$ acesso à intersubjetividade seria assim estreitamente ligado à possibilidade de um mantelamento das sensações, inicialmente desmanteladas.

Parece-nos, hoje, que o desmantelamento intersensorial de D. M. Meltzer, ou melhor, a possibilidade de mantelamento e a segmentação intra-sensorial rítmica que acabamos de descrever encontram-se, provavelmente, em relação dialética estreita.

Com efeito, reafirmamos, o mantelamento de sensações distintas não pode se operar a não ser por meio de uma compatibilidade do ritmo das sensações segmentadas, o mantelamento não correspondendo a uma simples soma das sensações, mas sim a uma organização complexa na qual o objeto materno, seu funcionamento interativo e sua linguagem desempenham um papel de continência e de transformação essencial (W.R. Bion).

Existiriam, no entanto, duas modalidades de segmentação principais: uma central e outra periférica.

A segmentação central remete, no fundo, à periodicidade dos processos de atenção da qual Freud fala em seu artigo intitulado "Formulações sobre os dois princípios do funcionamento mental" (1911), e tal como trata novamente no artigo sobre "A negação" (1925): "A percepção não é um processo puramente passivo, mas o ego envia periodicamente para o sistema de percepção, pequenas quantidades de investimento graças às quais ele degusta os estímulos externos para, após cada uma dessas incursões exploratórias, retirar-se de novo".

Distúrbios da segmentação central poderiam ser evocados no campo do autismo infantil (trabalhos sobre o funcionamento da substância reticulada do tronco cerebral), como também no campo da hiper-atividade, mas, antes de tudo, é preciso também levar em conta o papel do objeto que tem, por seu lado, uma função facilitadora ou obstrutora desta segmentação rítmica dos fluxos sensoriais.

Sabemos hoje que uma falta de sincronia das interações pode perturbar o acesso da criança a uma exploração dirigida de seu ambiente (alvos inicialmente variáveis, depois o rosto da mãe e, por fim, objetos terceiros).

Por esse fato a segmentação é também periférica, fundada sobre a congruência do ritmo das interações e sobre a sincronia destas com as capacidades próprias de segmentação do bebê (piscar das pálpebras, movimentos oculares, descontinuidade do toque...)

Por fim, podemos avançar a idéia de que a partir de uma segmentação bemsucedida dos diversos fluxos sensoriais (segmentação central e periférica), o mantelamento deles torna-se possível pela articulação profunda das diferentes modalidades perceptivas graças à dimensão integrativa das interações.

A partir daí, o bebê pode ser o ator de sua maneira de tratar as informações provenientes de seu ambiente, e abre-se para ele a possibilidade de um acesso à 
intersubjetividade (só um objeto mantelado pode ser percebido como distinto), e daí à linguagem.

Formas fixas, movimentos e afetos

Não há palavra possível sem abertura sobre o exterior.

A potencialidade de uma exterioridade é uma condição sine qua non para que possa, um dia, emergir a linguagem a partir do acesso à intersubjetividade da qual acabamos de lembrar alguns fundamentos.

Nas linhas que se seguem, quando falamos do exterior, trata-se ainda somente de uma potencialidade que só se atualizará no estabelecimento de uma linha de demarcação cuja gênese remete a toda a dinâmica examinada por S. Freud em seu trabalho sobre "A negação".

O bebê organiza-se com dois tipos de informações necessárias e suficientes, e que devem ser concomitantes na medida em que nenhuma percepção de movimento pode se fazer sem referência a uma forma fixa. ${ }^{5}$

- As formas fixas (contorno externo do rosto da mãe, nariz, sensação das costas apoiadas...) devem ser experimentadas pelo bebê como potencialmente exteriores a ele mesmo.

- Os movimentos são tratados e integrados, nós o dissemos, por uma percepção co-modal ritmada, e é importante igualmente que o bebê possa sentilos como se inscrevendo em um fora ainda em construção. Se a co-modalidade perceptiva é menos eficaz, a busca da forma fixa é, sem dúvida, menos fácil.

Mas se o bebê tem necessidade de um exterior potencial para construir sua palavra, ele tem igualmente necessidade de um sistema referencial com valor organizador de suas percepções.

Parece-nos que esse lugar das formas fixas e dos movimentos suscetíveis de desempenhar um papel organizador para o bebê é, por essência, o corpo da mãe, com toda sua dinâmica, e particularmente seu rosto, corpo e rosto encontrando-se animados por sua linguagem, e pelos afetos que a habitam e que vão permitir ao bebê edificar uma verdadeira semiologia do afeto.

O afeto é, então, o fator principal que de um lado unifica o que emana da mãe, e, de outro, mantém uma diversidade da informação ao nível das cinco modalidades sensoriais.

5. A criança autista que não pode localizar com suficiente rapidez um ponto fixo exterior no momento em que seu corpo é colocado em movimento a partir de fora (via o ritmo do corpo da mãe, por exemplo), só pode agarrar-se às sensações internas, formas fixas internas de certo modo, mesmo se o dentro e o fora estão ainda mal diferenciados para ela. 
Assim reencontramos todos os trabalhos de D.N. Stern sobre os mecanismos da "afinação afetiva" (ou "harmonização dos afetos") que sublinham claramente uma junção estreita entre o afeto e o movimento.

Retorno à linguagem

Mesmo se o leitor está com a impressão de que nossas considerações nos levaram um pouco longe da questão do surgimento da linguagem, na realidade esse desvio aparente nos era absolutamente necessário para fazer sentir até que ponto a emergência da linguagem da criança se enraíza no vivo da construção de seu mundo interno.

Trata-se de um verdadeiro trabalho de organização da forma que a criança é levada a fazer a partir de sua percepção das formas e dos movimentos, nela e no outro, e é por isso que evocamos, a esse respeito, o conceito de neoestruturalismo das formas fixas e dos movimentos.

$\mathrm{O}$ bebê percebe formas e movimentos dos quais ele não conhece a fonte e dos quais ele deve perceber a estrutura íntima que só pode ser uma estrutura de tipo dinâmico. As palavras da linguagem da mãe (ou do familiar) constituem provavelmente sua fonte organizadora escondida.

Quando o pai, ou a mãe, falam ao seu bebê, a linguagem enquanto tal fica, de uma certa maneira, escondida, escondida porque a linguagem é o ser mesmo: somente os movimentos e as formas fixas podem ser oferecidas e transmitidas à percepção do bebê.

É somente em um segundo tempo que as palavras do adulto serão integradas pelo bebê em função de seus processos de apropriação, e no contexto de um autêntico ato de autonomização.

A linguagem em sua forma global não é transmissível enquanto tal.

As palavras do pai e da mãe constituem somente - mas isso é essencial a estrutura que inicia e organiza as formas e os movimentos dos quais o bebê se apropriará ulteriormente.

Assim, o bebê percebe e se apropria das formas e dos movimentos que compõem uma estrutura vazia, aquela da linguagem por vir e ainda potencial.

\section{Conclusões}

Ao término destas páginas nas quais nós avaliamos o aspecto ainda inacabado e parcialmente hipotético, parece-nos ser útil reformular nossos objetivos. 
Quisemos mostrar que a possibilidade de emergência da linguagem verbal da criança origina-se fundamentalmente em suas capacidades de narração analógica e pré-verbal, e que estas se encontram ligadas de maneira estreita à dinâmica de seu acesso à intersubjetividade.

Os mecanismos de mantelamento intersensorial e de segmentação intrasensorial das percepções advindas das diferentes modalidades sensoriais equilibram-se no seio de uma dialética estreita e profunda, para permitir a instalação da intersubjetividade sem a qual não há abertura possível para o terceiro, e nem possibilidade de emergência da linguagem. O papel do objeto é aqui essencial, pois vai oferecer as condições rítmicas interativas do mantelamento das percepções obrigatoriamente segmentadas, já que não pode haver percepção sem descontinuidade.

Essas reflexões levam ao reconhecimento obrigatório de um estruturalismo dinâmico da intrincação funcional entre formas fixas e movimentos (de si como do outro), e não mais de um estruturalismo dos estados, cujo aspecto excessivamente congelado não faz justiça ao sutil trabalho psíquico do bebê.

A linguagem verbal do adulto não é transmitida enquanto tal ao bebê, mas somente pela via das formas fixas e dos movimentos, cuja percepção ritmada pela criança organiza nela uma autêntica semiologia do afeto.

Dito ainda de outra formaa, a linguagem verbal do adulto, paradoxalmente, retira de sua parte escondida a eficácia de sua transmissão.

É graças à sua "interpretação" estrutural dinâmica dos movimentos e das formas fixas perceptíveis no seio de seu ambiente (incluindo o outro e ele mesmo) que ele poderá afetar a linguagem do adulto, e secundariamente, a sua própria linguagem, o corpo e o rosto da mãe jogando então como organizador contextual central neste trabalho de marcação (reconhecimento) e de organização estrutural.

\section{Resumos}

Después de recordar las bases de la comunicación analógica y digital, los autores presentan las hipótesis de su programa de investigación actual a respecto de los precursores corporales y de comportamiento del acceso al lenguaje verbal en los niños. El análisis del mirar, de las vocalizaciones y de los movimientos de las manos del bebé son los principales elementos estudiados en esta investigación en colaboración. El surgimiento de la inter subjetividad parece depender fundamentalmente de un equilibrio entre los procesos de desmantelamiento ínter sensorial y de segmentación intra sensorial de los diferentes flujos perceptivos.

Palabras claves: Bebé, comunicación, lenguaje, flujos sensoriales 
Après avoir rappelé les bases de la communication analogique et digitale, les auteurs présentent les hypothèses de leur programme de recherche actuel sur les précurseurs corporels et comportementaux de l'accès au langage verbal chez l'enfant. Les analyses du regard, des vocalisations et des mouvements des mains du bébé sont les principaux éléments étudiés dans cette recherche collaborative.

L'avènement de l'intersubjectivité semble dépendre fondamentalement d'un équilibre entre les processus de démantèlement inter-sensoriel et de segmentation intrasensorielle des différents flux perceptifs.

Mots cles: Bébé, communication, langage, flux sensoriels

This article begins with a summary of the bases for analogical and digital communication. The authors then present hypotheses for their current research program on the physical and behavioral precursors of access to verbal language in the child. Analyses of the baby's gaze, vocalization and hand movements are the main aspects studied in this joint research. The emergence of intersubjectivity seems to depend basically on a balance between the processes of intersensorial dismantling and of intrasensory segmentation of the different flows of perception.

Key words: Baby, communication, language, sensory flows

Versão inicial recebida em janeiro de 2005

Versão revisada recebida em fevereiro de 2005 